\title{
Effect of nickel-based laser coatings on phase composition and corrosion behaviour of titanium alloy for offshore application
}

\author{
O.S. Adesina ${ }^{\mathrm{a}, \mathrm{b}, *}$, M. Oki ${ }^{\mathrm{b}}$, G.A. Farotade ${ }^{\mathrm{a}}$, O.T. Adesina ${ }^{\mathrm{c}}$, O.F. Ogunbiyi ${ }^{\mathrm{c}}$, A.A. Adeleke $^{\mathrm{b}}$ \\ ${ }^{a}$ Department of Chemical, Metallurgical E Materials Engineering, Tshwane University of Technology, P.M.B. X680, Pretoria 0001, South Africa \\ ${ }^{\mathrm{b}}$ Department of Mechanical Engineering, Landmark University, Omu - Aran, Kwara - State, Nigeria \\ ${ }^{\mathrm{c}}$ Department of Mechanical and Automation Engineering, Tshwane University of Technology, Pretoria, South Africa
}

\section{A R T I C L E I N F O}

\section{Article history:}

Received 29 January 2020

Received in revised form 22 April 2020

Accepted 23 April 2020

Available online $\mathrm{xxxx}$

\section{Keywords:}

Surface degradation

Corrosion behaviour

Phase composition

Titanium alloy (Ti-6Al-4V)

Offshore application

\begin{abstract}
A B S T R A C T
Recent advances in titanium alloy applications in the offshore industry have been realized through the development of laser surface modification technique. The distinctive outcome of this technique has provided increase in the utilization of titanium in offshore drilling risers for special drilling operations and various subsea and tubing applications. In this work, surface mitigation and corrosion degradation of titanium alloy in aggressive sulfuric acid were investigated using electrochemical technique (linear potentiodynamic polarization) while the surface characterization (morphology) and phases of the resultant coatings were analyzed using X-ray diffractometry (XRD) and scanning electron microscopy (SEM). Prior to that, laser surface technique was used to fabricate Nickel-based powder on the substrate (Ti$6 \mathrm{Al}-4 \mathrm{~V}$ ). Results revealed that laser clad sample with high scan speed was more effective in improving the corrosion resistance compared to low scan speed. The enhanced corrosion resistance with high laser scan speed has been attributed to the presence of hard intermetallic compounds in the metallic coating. (c) 2020 Elsevier Ltd. All rights reserved.

Selection and peer-review under responsibility of the scientific committee of the International Sympo-
\end{abstract} sium on Nanostructured, Nanoengineered and Advanced Materials.

\section{Introduction}

Titanium (Ti-6Al-4V) alloy has extensive application in marine and petro-chemical industries due to its high specific strength and good corrosion resistance properties [1]. The good corrosion resistance of Ti-6Al-4V alloy in a wide variety of environment such as saline, halides and in most oxidizing environment has been attributed to the stable, high adhere and continuous protective film known as $\mathrm{TiO}_{2}$ passive film oxide. The oxide layer can be rapidly and spontaneously formed on the surface, which protects Ti-6Al$4 \mathrm{~V}$ from deterioration. According to Contu et al. [2], whenever there is any amount of air or water in a process steam, the oxides film forms and protects the metal from attack and if the film is damaged, the metal surface instantly repair itself. This resistance justifies its use in tubing for heat exchanger and steam raising industries. However, passive behavior of Ti-6Al-4V alloy in

\footnotetext{
* Corresponding author at: Department of Chemical, Metallurgical \& Materials Engineering, Tshwane University of Technology, P.M.B. X680, Pretoria 0001, South Africa.

E-mail address: osaadesina@yahoo.com (O.S. Adesina).
}

sulphuric and hydrochloric acid has been a major concern by many researchers [2].

Researchers have hypothesized that the corrosion or passive behaviour could be influenced by the presence of intermetallics, reactive oxides during laser deposition as well as the reductive and oxidative reactions between the coatings and the medium. For illustration, Mogoda et al. [3] investigated the anodic dissolution of Ti-6Al-4V in sulphuric acid. The authors found that Ti$6 \mathrm{Al}-4 \mathrm{~V}$ alloy dissolved directly as $\mathrm{Ti}^{3+}$ without any soluble oxide formed on the surface. Surface modification techniques such as laser cladding technique have been employed to fabricate coatings with advanced mechanical and corrosion properties in metal surface improvement [4]. Laser cladding is surface melting process in which the laser beam is used to fuse an alloy addition onto a substrate. The addition of $\mathrm{Ni}$ [5] in laser cladding of Co is expected to produce complex phases of $\mathrm{CoNi}$ intermetallic with a wide range of superior and functional properties. Ni possess very excellent corrosion resistance due to its abilities to form oxide layers while the cobalt has exceptional corrosion resistance in acidic environment (that is, preventing the dissolution of the passive oxide), high resistance to oxidation, nitriding, and sulfidation [6]. Thus, the need to produce a modified surface via reinforcing that is deficient of such 
passive film layer. This research centered on the electro-chemical behavior and phase composition of $\mathrm{Ni}$ - based laser coatings on Ti-6Al-4V Alloy.

\section{Experimental}

\subsection{Materials and coating preparation}

In this study, Ti-6Al-4V plates were used as substrates $(50 \times 50 \times 5 \mathrm{~mm})$. The substrates were sandblasted by spraying them with $\mathrm{SiO}_{2}$ grit sand and cleaned with acetone before exposure to laser beam to influence absorptivity of the laser beam radiation. LSC experiment was carried out using a continuous wave $4.4 \mathrm{~kW}$ Rofin Sinar Nd:YAG laser. The processing parameters used were 30Co-70Ni ad-mixed, laser power of $900 \mathrm{~W}$; scan speed of 0.6$1.2 \mathrm{~m} / \mathrm{min}$; powder feed rate $1.0 \mathrm{~g} / \mathrm{min}$; beam spot size $3 \mathrm{~mm}$; gas flow rate $1.2 \mathrm{~L} / \mathrm{min}$. In the course of laser cladding process, the molten pool was protected by argon gas flowing at $3 \mathrm{~L} / \mathrm{min}$. This was done in order to prevent oxidation as Ti has high affinity for oxygen.

\subsection{Microstructural characterization and corrosion measurement}

The microstructures of the laser clad coatings were analyzed by scanning electron microscope (FE-SEM JSM-7600F) while the phases were examined using Philips PW1713 X-ray diffractometer (XRD) fitted with monochromatic $\mathrm{CuK} \alpha$ radiation set at $40 \mathrm{Kv}$ and $20 \mathrm{~mA}$, while phase identification was done using Philips Analytical X'Pert High Scores software fitted with an in built (ICSD) database. The electrochemical behavior of the specimen was studied $0.5 \mathrm{M} \mathrm{H}_{2} \mathrm{SO}_{4}$ environment at room temperature using the potentiodynamic polarization method at scan rate of $2 \mathrm{mV} / \mathrm{S}$ starting from $-1.0 \mathrm{~V}$ (with respect to the OCP) to about $1.2 \mathrm{~V}$. Platinum rod was used as the counter electrode and a silver/silver chloride $(3 \mathrm{M} \mathrm{KCl}$ ) as the reference electrode (SSE). The electrochemical parameters were calculated by analyses of the Tafel region using the General Purpose Electrochemical Software (GPES) version 4.9.

\section{Results and discussion}

\subsection{Microstructure analyses}

Fig. 1 shows the SEM micrograph of the substrate with EDS; the EDS revealed the $\mathrm{Ti}, \mathrm{V}$ and $\mathrm{Al}$ as elements present in the substrate with $\mathrm{Ti}$ as the major constituent. From the micrograph of the Ti6Al4V alloy, the background is the primary alpha phase while the whitish looking substances are the lamellar transformed beta phase.

Fig. 2a and b presents the microstructural evolution of synthesized $30 \mathrm{Co} / 70 \mathrm{Ni}$ coatings at $0.6 \mathrm{~m} / \mathrm{min}$ and $1.2 \mathrm{~m} / \mathrm{min}$ both at $900 \mathrm{~W}$. The different in microstructural evolution of the synthesized coatings are brought by the variation of scan speed which mostly results in unique solidification rates, thus leading to the development of different unique micrographs as observed in Fig. 2a and b. Both fabricated coatings resulted in nonhomogenous grains, free from pores and cracks or no initiation of stress. Larger grain size is seen in Fig. 2a could be attributed to slow scan speed which resulted in the sample been subjected to heat for a longer period of time while on the other hand, Fig. $2 b$ was subjected to fast cooling of the melt pool and there was less time for grain growth, hence the micrograph indicates small grain size and also the formation of dendritic grain shape.

\subsection{Microstructure after corrosion test}

Fig. 3 shows the SEM morphologies of the Co-Ni coatings after corrosion. More dense passive oxide layers could be observed mostly on higher scan while thin film was observed on lower scan speed. According to Sharifi and Ghorbani [7], Co-Ni coatings has different structural phases consisting of FCC for pure nickel, HCP for pure cobalt as well as FCC and HCP phases as cobalt content increases. The passive oxide layers aid corrosion resistance of the coatings as a result of simultaneous effects of Co-Ni elements which increase passivation $[8,9]$. Formation of micro-galvanic passive oxides on the surface of the coating after corrosion helps to inert physical barriers to the corrosion initiation or further growth

Table 1

Potentiodynamic polarization data of samples in $0.5 \mathrm{M} \mathrm{H}_{2} \mathrm{SO}_{4}$.

\begin{tabular}{|c|c|c|c|c|c|c|}
\hline Laser Parameters & Ecorr, Calc $(V)$ & Ecorr, Obs $(V)$ & $\operatorname{Jcorr}\left(A / \mathrm{cm}^{2}\right)$ & icorr $\left(A / \mathrm{cm}^{2}\right)$ & $\mathrm{CR}(m m / y r)$ & $\operatorname{Rp}\left(\Omega . \mathrm{cm}^{2}\right)$ \\
\hline Control & -0.24539 & -0.26757 & 0.00016067 & 0.00016067 & 1.3855 & 627.35 \\
\hline 30Co/70Ni0.6(900) & -0.06576 & -0.18997 & $2.28 \mathrm{E}-05$ & $2.28 \mathrm{E}-05$ & 0.19642 & 919.88 \\
\hline 30Co/70Ni1.2(900) & 0.34853 & 0.19491 & $8.13 \mathrm{E}-09$ & $8.13 \mathrm{E}-09$ & $7.01 \mathrm{E}-05$ & $3.82 \mathrm{E}+07$ \\
\hline
\end{tabular}

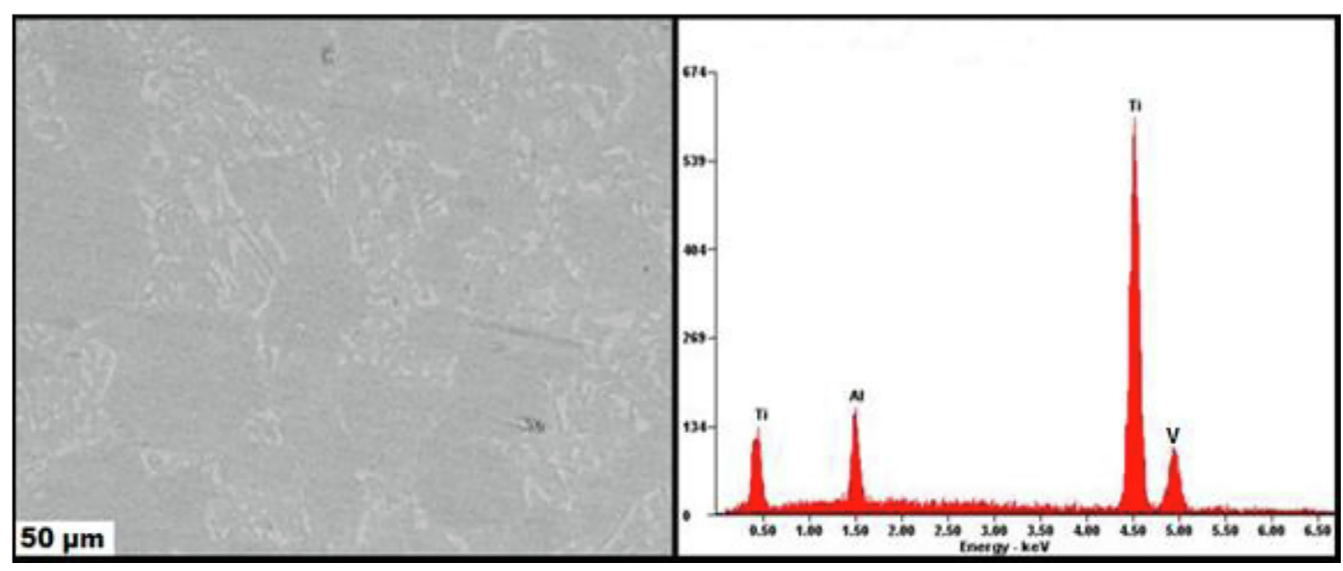

Fig. 1. Scanning Electron Micrograph and EDS of Ti6Al4V Alloy. 

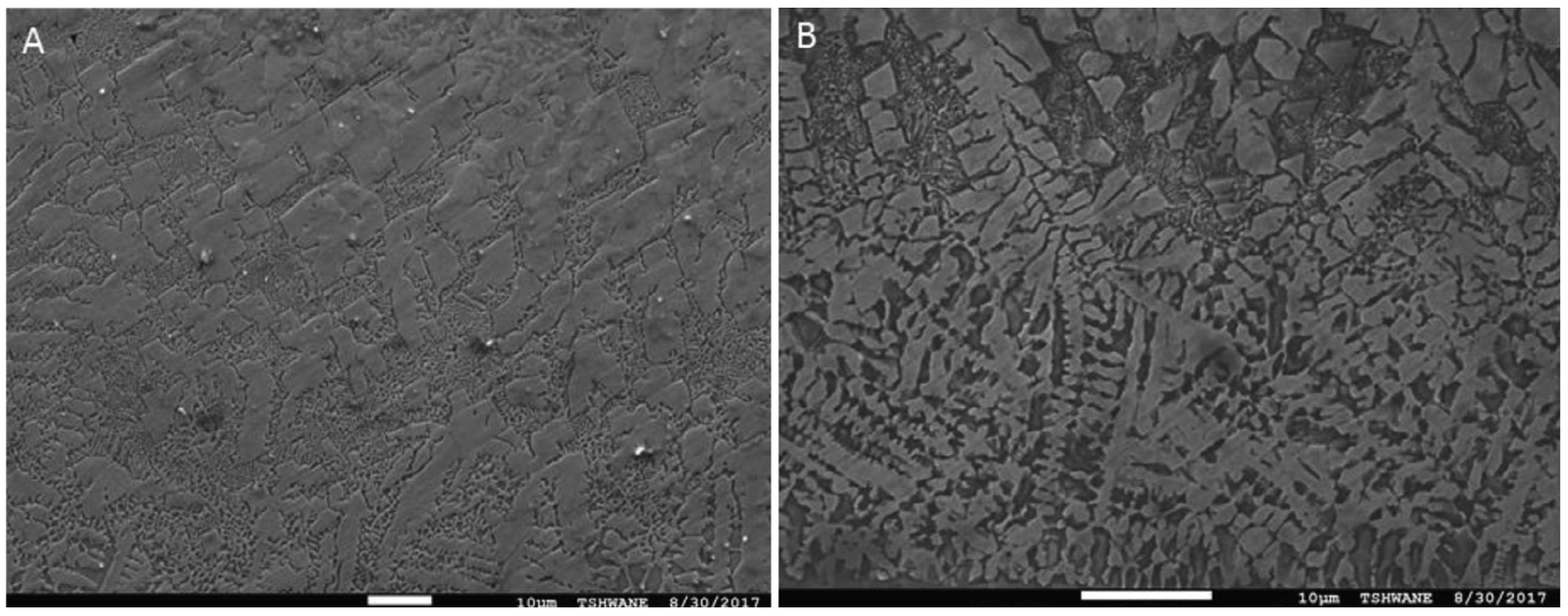

Fig. 2. Surface coating of: (a) $30 \mathrm{Co} / 70 \mathrm{Ni}$ at $0.6 \mathrm{~m} / \mathrm{min}$ and (b) $30 \mathrm{Co} / 70 \mathrm{Ni}$ at $1.2 \mathrm{~m} / \mathrm{min}$.
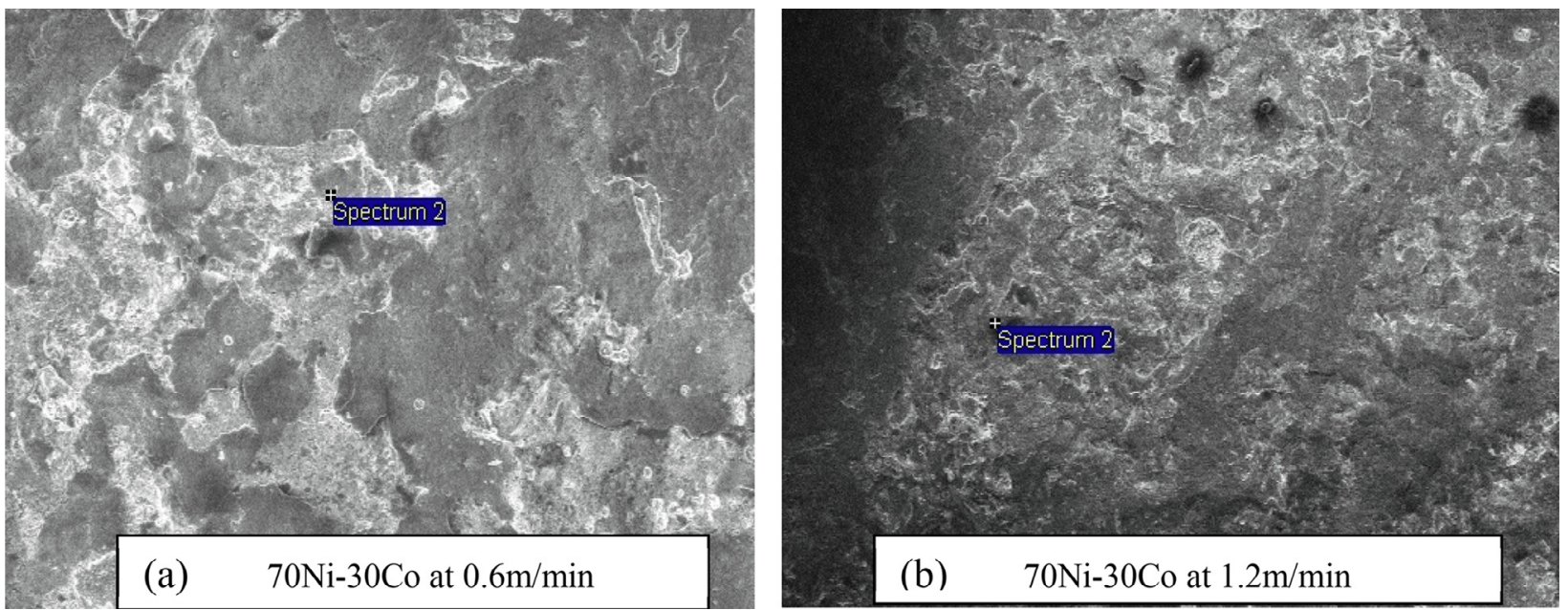

Fig. 3. SEM Micrographs of the Coated Samples after Corrosion (A) 30Co-70Ni -0.6 (B) 30Co-70Ni -1.2.

of corrosion products associated with sulphuric environment [10]. The presence of Titanium hydride exhibits excellent corrosion resistance in aggressive solutions and a high catalytic activity for several electrochemical processes [11]. In addition, Obadele et al. [4] explains that the chemical inertness of NiTi alloys as shown in Fig. 5 has the exceptional corrosion resistance due to the formation of a protective oxide layer preventing direct contact of the alloy with its environment.

\subsection{Electro-chemical analysis}

\subsubsection{Open-circuit potential (OCP) analysis}

A sequence of electrochemical tests was conducted to estimate the chemical stability of the Ti6Al4V substrate, laser clad $30 \mathrm{Co} / 70 \mathrm{Ni}$ at $0.6 \mathrm{~m} / \mathrm{min}$ and laser clad $30 \mathrm{Co} / 70 \mathrm{Ni}$ at $1.2 \mathrm{~m} / \mathrm{min}$ scan speed. These were the open circuit potential (OCP) in Fig. $4 \mathrm{a}$ and potentiodynamic polarization experiments in Fig. 4b. The OCP test showing a plot of potential against time in Fig. 4a indicates the corrosivity/passivity behaviour of the test samples. This was conducted at ambient temperature for the three samples in $0.5 \mathrm{~m} \mathrm{H} 2 \mathrm{SO} 4$ solution. The Potentiodynamic polarization data of samples in $0.5 \mathrm{M} \mathrm{H} 2 \mathrm{SO} 4$ is presented in (Table 1). From Fig. 4a, it was observed that the potentials curves show a similar pattern for the substrate and the laser clad $30 \mathrm{Co} / 70 \mathrm{Ni}$ at $0.6 \mathrm{~m} / \mathrm{min}$ and $1.2 \mathrm{~m} / \mathrm{min}$. A steady-state (stable) OCP values were quickly obtained from the beginning of the tests and its progress almost linearly for the $2 \mathrm{~h}$ duration of the experiments. This suggests that the potentials for the three samples reached the quasi-stationary values within the first few minutes of the study [12]. The observation suggests that there were rapid formation and growth of oxide film on the surface of the samples. Meanwhile, the film oxide formed on the surface of clad $30 \mathrm{Co} / 70 \mathrm{Ni}$ at a scan speed of $1.2 \mathrm{~m} / \mathrm{min}$ displayed the most positive potential value. This is in comparison with the substrate and the alloy that was clad with $30 \mathrm{Co} / 70 \mathrm{Ni}$ at a scan speed of $0.6 \mathrm{~m} / \mathrm{min}$. The closeness of the corrosion potential value to the positive pole suggest the formation of a protective passive film (stable oxide film). Therefore, the dissolution of metal is suppressed, and the corrosion rate is reduced through the barrier layer formed by the passive film $[13,14]$. On this basis using $0.5 \mathrm{~m} \mathrm{H} 2 \mathrm{SO} 4$ solution, the Ti6Al4V alloy clad with $30 \mathrm{Co} / 70 \mathrm{Ni}$ at a scan rate of $1.2 \mathrm{~m} / \mathrm{min}$ possess better corrosion resistance property.

\subsubsection{Potentiodynamic polarization study}

Fig. 4b illustrates the potentiodynamic polarization curves of $30 \mathrm{Co} / 70 \mathrm{Ni}$ laser cladded on Ti-6Al-4V substrate at scan speeds 


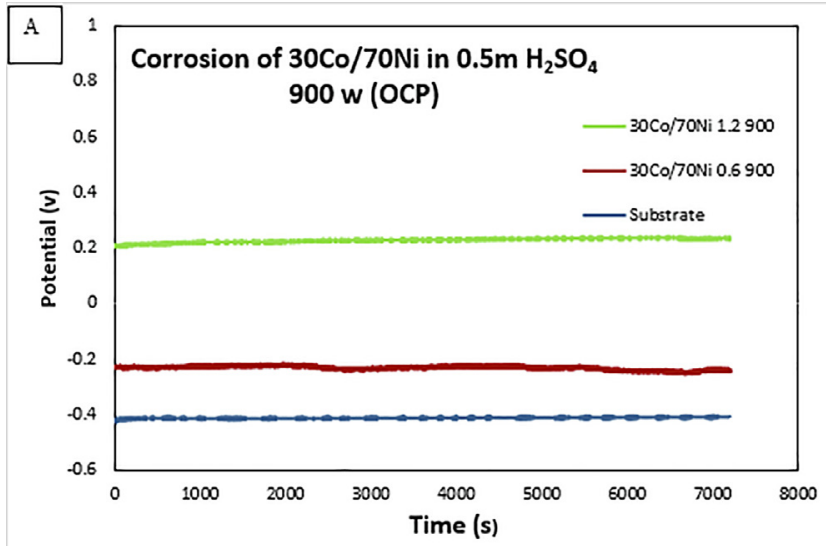

Fig. 4a. Open-circuit potential (OCP) versus time of the Ti6Al4V substrate and laser clad $30 \mathrm{Co} / 70 \mathrm{Ni}$ at $0.6 \mathrm{~m} / \mathrm{min}$ and $1.2 \mathrm{~m} / \mathrm{min}$.

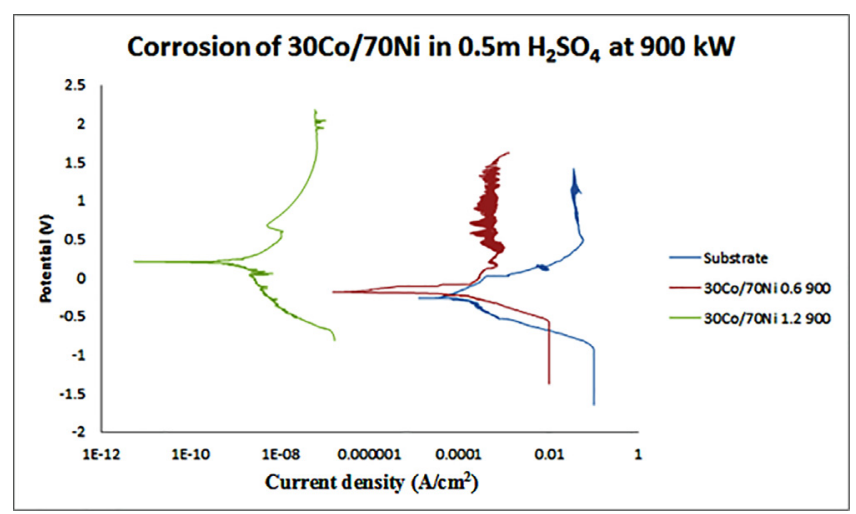

Fig. 4b. Potentiodynamic polarization curves of Ti6Al4V substrate and laser clad $30 \mathrm{Co} / 70 \mathrm{Ni}$ at $0.6 \mathrm{~m} / \mathrm{min}$ and $1.2 \mathrm{~m} / \mathrm{min}$.

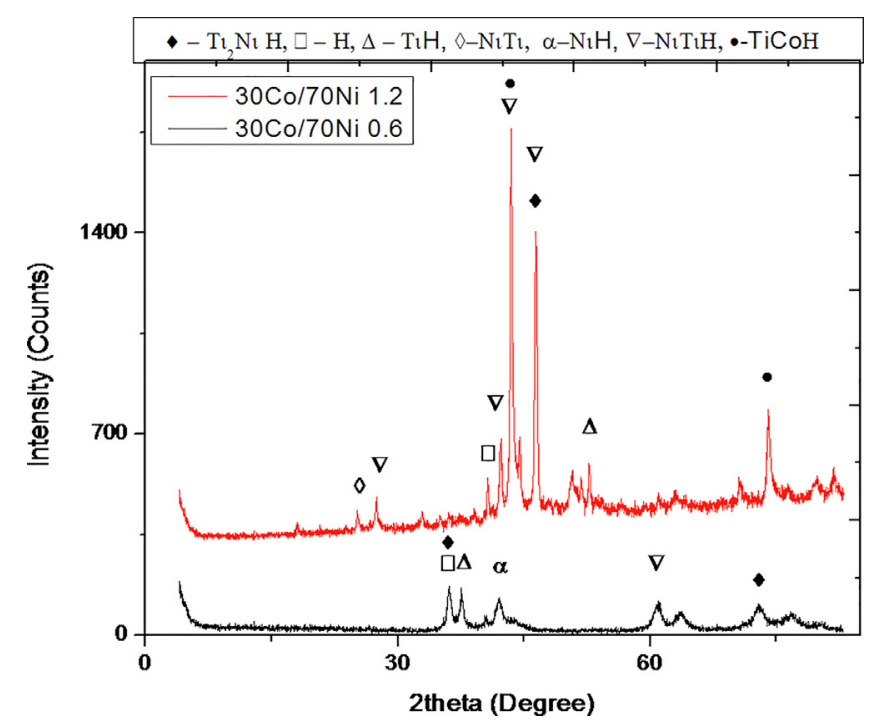

Fig. 5. X-ray diffraction analysis of laser Clad 30Co-70Ni clad samples.

0.6 and $1.2 \mathrm{~m} / \mathrm{min}$ both at laser power of $900 \mathrm{~W}$. An increase in laser scan speed resulted in corrosion current density of the fabricated coatings declining from $2.28 \mathrm{E}$ to $05 \mathrm{~mA}$ to $8.13 \mathrm{E}-09 \mathrm{~mA}$, thus revealing the effect of laser speed on corrosion current of $30 \mathrm{Co}-$
$70 \mathrm{Ni}$ alloy. The polarization resistance (Rp) recorded is in accordance with the visual behavior plot, where, 30Co-70Ni deposited at $1.2 \mathrm{~m} / \mathrm{min}$ exhibited a positive shift in polarization potential and a decreased corrosion rate of $7.01 \mathrm{E}-05 \mathrm{~mm} / \mathrm{yr}$ compared to 30 Co-70Ni deposited at $0.6 \mathrm{~m} / \mathrm{min}$ with a higher corrosion rate of $0.19642 \mathrm{~mm} / \mathrm{yr}$. From the Fig. $4 \mathrm{~b}$, there is a slight passivation trend over the range of potentials for the substrate on the anodic branch. However, Ti-6Al-4V is known to form protective film on the alloy surface which turns to slow down/stop accelerated electrochemical surface deterioration $[15,16]$. The anti-corrosion of fabricated coatings may be linked to simultaneous effects of important factors, for instance chemical composition, phase structure, grain size and preferred orientation [10]. As shown in Fig. 3, the grain boundaries show no sign of micro pores, no cracks and intermediate homogeneity of the fabricated is displayed on both $0.6 \mathrm{~m} / \mathrm{min}$ and $1.2 \mathrm{~m} / \mathrm{min}$ samples. $30 \mathrm{Co} / 70 \mathrm{Ni}$ at $0.6 \mathrm{~m} / \mathrm{min}$ is represented by $\mathrm{Ti}_{2} \mathrm{Ni}, \mathrm{TiH}, \mathrm{NiTi}, \mathrm{NiH}, \mathrm{NiTiH}$ and $\mathrm{TiCoH}$ phases as shown Fig. 5.

\subsection{Phase (XRD) analysis after corrosion test}

The XRD patterns displayed in Fig. 5 clearly shows that the phases formed in these coatings differ significantly, as a result of varying laser parameters. The XRD spectrum revealed phases of by $\mathrm{Ti}_{2} \mathrm{Ni}, \mathrm{TiH}, \mathrm{NiTi}, \mathrm{NiH}, \mathrm{NiTiH}$ and $\mathrm{TiCoH}$. Intermetallic phases of $\mathrm{NiTiH}$ and $\mathrm{Ti}_{2} \mathrm{Ni}$ were identified as dominant phases in the spectrum. Weng et al. [17] stated that high energy radiated by the laser beam lead to molten powders interactions with substrate, thereby yielding complex chemical reactions. Consequently, emanation of $\mathrm{Ti}$ and other alloying elements from the substrate at both scan speeds indicates sufficient energy intensity to encourage intense material diffusion and mixing between the substrate and the coating [18].

\section{Conclusion}

Corrosion behavior and phase composition of $\mathrm{Ni}$ - based laser coatings on Ti-6Al-4V Alloy have been investigated. Based on the results obtained from the study, the following conclusions could be drawn:

1. Coatings produced a crack free, dense and strong metallurgical with significant effect on the corrosion properties.

2. XRD analysis confirms the presence of phases of $\mathrm{Ti}_{2} \mathrm{Ni}, \mathrm{TiH}, \mathrm{NiTi}$, $\mathrm{NiH}, \mathrm{NiTiH}$ and $\mathrm{TiCoH}$ phases. The formation was as a result of high energy radiated by the laser beam lead to molten powders interactions with substrate, thus yielding complex chemical reactions.

3. Laser clad coatings exhibited active-passive behavior in sulfuric environment. Higher scan speed enhanced the corrosion resistance by formation of more dense passivity.

\section{CRediT authorship contribution statement}

O.S. Adesina: Conceptualization, Methodology, Writing - original draft. M. Oki: Supervision. G.A. Farotade: Conceptualization, Methodology, Writing - original draft, Validation. O.T. Adesina: Conceptualization. O.F. Ogunbiyi: Writing - review \& editing. A.A. Adeleke: Writing - review \& editing.

\section{Declaration of Competing Interest}

The authors declare that they have no known competing financial interests or personal relationships that could have appeared to influence the work reported in this paper. 


\section{Acknowledgements}

This research is supported by the National Laser Centre (NLC), Council for Scientific and Industrial Research (CSIR), Pretoria, South Africa.

\section{References}

[1] B. Song, S. Dong, B. Zhang, H. Liao, C. Coddet, Mater. Design 35 (2012) 120-125.

[2] F. Contu, B. Elsener, H. Böhni, Corr. Sci. 46 (2004) 2241-2254.

[3] A. Mogoda, Y. Ahmad, W. Badawy, J. Appl. Electrochem. 34 (2004) 873-878.

[4] B.A. Obadele, M.L. Lepule, A. Andrews, P.A. Olubambi, Tribo. Int. 78 (2014) 160167.

[5] Y.-Z. Zhang, Y. Tu, M.-Z. Xi, L.-K. Shi, Surf. Coat. Tech. 202 (2008) 5924-5928.

[6] K.H. Kim, S.H. Lee, N.D. Nam, J.G. Kim, Corr. sci. 53 (2011) 3576-3587.
[7] K. Sharifi, M. Ghorbani, Bullet. Mater. Sci. 37 (2014) 713-719.

[8] N.D. Tomashov, Passivity Springer Sci. Buss. Media (2012).

[9] N. Tomashov, Corrosion 14 (1958) 39-46.

[10] B. Bakhit, A. Akbari, F. Nasirpouri, M.G. Hosseini, App. Surf. Sci. 307 (2014) $351-359$

[11] E. Gómez, S. Pané, E. Vallés, Electrochem. Acta 51 (2005) 146-153.

[12] A. Boucheham, A. Karaali, M. Berouaken, Y. Larbah, урнал нано-та електронної фізики 8 (2016) 1-6.

[13] Y. Abdelrhman, M.A.-H. Gepreel, S. Kobayashi, S. Okano, T. Okamoto, Mater. Sci. Eng. C 99 (2019) 552-562.

[14] O. Ogunbiyi, T. Jamiru, R. Sadiku, L. Beneke, O. Adesina, J. Fayomi, Int. J. Adv. Manuf. Tech. 104 (2019) 4195-4206.

[15] L. Hu, J. Li, Y. Tao, Y. Lv, Surf. Coat. Tech., 311 (2017) 295-306.

[16] O. Ogunbiyi, T. Jamiru, R. Sadiku, L. Beneke, O. Adesina, B.A. Obadele, J. Bio. Tribo Corr. 6 (2020) 1.

[17] F. Weng, H. Yu, C. Chen, J. Dai, Mater. Design 80 (2015) 174-181.

[18] S.Z. Shuja, B.S. Yilbas, Optics Laser Tech. 43 (2011) 767-775. 